\title{
How to Approach a Clinical Case from a Medical Student Perspective
}

Jesus D. Sendoya Vargas, ' Laura L. Fernandez Camacho. ${ }^{1}$

\section{The Experience}

The undergraduate degree in medicine in Colombia lasts six years of which the first two are theoretical subjects such as molecular biology, biophysics, biochemistry, anatomy, and physiology. ${ }^{1}$ We start clinical subjects in the third year; in Neiva Huila, we have a third level public hospital where we carry out practical training, and where we have our first contact with patients. ${ }^{1-2}$

The main lesson to be learnt on entering the medical profession for the first time is the importance of establishing an excellent doctor-patient relationship; from which we can derive a full understanding of what ails our patient in order to achieve their relief. 3 We have to generate trust in our patients through proper communication by directing the interrogation and so achieving an adequate medical history and physical examination; sometimes medical jargon can be a limitation. Most of the patients who attend Neiva Hospital have limited resources and have not even attended primary school, this is why students must be able to translate the patient's language into medical technical language, and vice versa in order to understand what the patient is referring to and to make sure that the patient understands the recommendations that we give. ${ }^{1-2}$ This is why the adaptation of medical students to clinical sciences and their context can become a bit complex. Within this environment of clinical sciences subjects, such as internal medicine, pediatrics, and gynecology, medical exercises called clinical cases appear.

In these exercises, a compelling case is presented with all the sociodemographic data, history of the disease, antecedents, physical examination and there may or may not be laboratory data and imaging; sometimes the information given is so extensive so that often we do not know how to approach it in order to create a diagnostic route. $3-5$ We have so much knowledge acquired over the years, but we are stil without a scheme of how to address the clinical case. To help form this scheme, we propose the following algorithm (Figure 1). 1, 4-6

STEP 1: First, within the clinical case, we will look for the chief ailment; it tells us the main symptoms the patient is complaining of and which limits his functional capacity and made him go to the hospital in the first place. It will allow us for the first time to frame diagnostic options in a specific anatomical place or system.3.5 Symptoms within the principal ailment can be so diverse that they may be associated with many pathologies, so it is necessary to take into account the history of the present illness. The history of the present illness is a detailed description of each symptom in chronological order of appearance. Each one of those will have specific characteristics of interest for the clinician, for example in case of pain we will be interested in its onset, location, intensity, quality, radiation, alleviating or aggravating together with associated symptoms. Patients can forget symptoms when relating the history of their disease, so the clinician interrogates in the review of systems for the most common symptoms of each system and those that he considers relevant for the differential diagnoses he has in mind. At this point, it may have been possible to locate and have the suspicion of several differential diagnostics that the exposed symptomatology may present. Therefore, during the physical examination, the clinician actively searches for signs in order to reach a semiological diagnosis through inspection, palpation, percussion, and auscultation of each system ;sometimes some signs are specific to a disease, and we can give an immediate diagnosis, but most of the time, these signs are not enough. 3.5

STEP 2: The anamnesis also allows us to know the past medical history of the patient. If we have some differential diagnoses from step one, the patient's past medical history often increases the likelihood that the current disease is related to one of those, so taking them into account is very important. Therefore, we must analyze past illnesses, childhood diseases, accidents, hospitalizations and previous surgeries, blood transfusions, regular medicines, allergies, habits, family diseases, sexual and social history..$^{-6}$ If we want to give a proper approach to the clinical case it is essential to relate if the current illness is a consequence of a past medical procedure, an adverse reaction to a medication, accidents, sequels of diseases or if there is a possibility of a genetic component associated to his pathology. We have to analyze the patient globally to find the intrinsic or extrinsic risk factors which can cause new differential diagnoses or reinforce those suspected in step $1.3,7$

STEP 3: Epidemiology plays an essential role in our diagnostic path because it can be determinant for the development of a disease and helps reduce possible diagnoses based on the factors that the patient has and which are common to the average person who may have the disease already diagnosed. Among these factors, we find: the age factor - since in each age group the most prevalent diseases varies; the race factor - which may imply a genetic predisposition to present different pathologies; the sex factor - since there are much more prevalent diseases in either of the two sexes which could help us to give preference to some possible diagnoses over others.3.5-7 Last but not least is the necessity for trips to suspected areas where a particular disease is endemic because of the high probability of the diseases' occurrence due to exposure to a sick population, vectors or contaminated environment. ${ }^{8}$

STEP 4: At the end of the data collection previously proposed, there is a high probability that a definitive diagnosis has already been reached, however, there are cases in which several pathologies may be equally likely, at this time it is appropriate to rely on the sensitivity and specificity of paraclinical.9-10,12 It is necessary to clarify that a paraclinical with high sensitivity has a higher performance when it is negative because with a high degree of certainty it can rule out several pathologies. Whereas a paraclinical with high specificity has higher performance when it is positive. ${ }^{11-12}$ However, it is important to say that

\section{Medical Student, Surcolombiana University, Neiva, Colombia.}




\section{Experience}

if paraclinical are not conclusive and clinical suspicion continues, it is recommended to continue the investigation. ${ }^{13}$

We must know that algorithms are handy tools when starting a task while acquiring expertise, but we must bear in mind that patients can become so complex and unique that not all fit into an algorithm and that is why the correct diagnosis is part of the art of medicine. ${ }^{3}$

Figure 1. Four Steps to Diagnosis. An Algorithm to Accomplish a Correct Approach and Diagnosis of a Clinical Case.

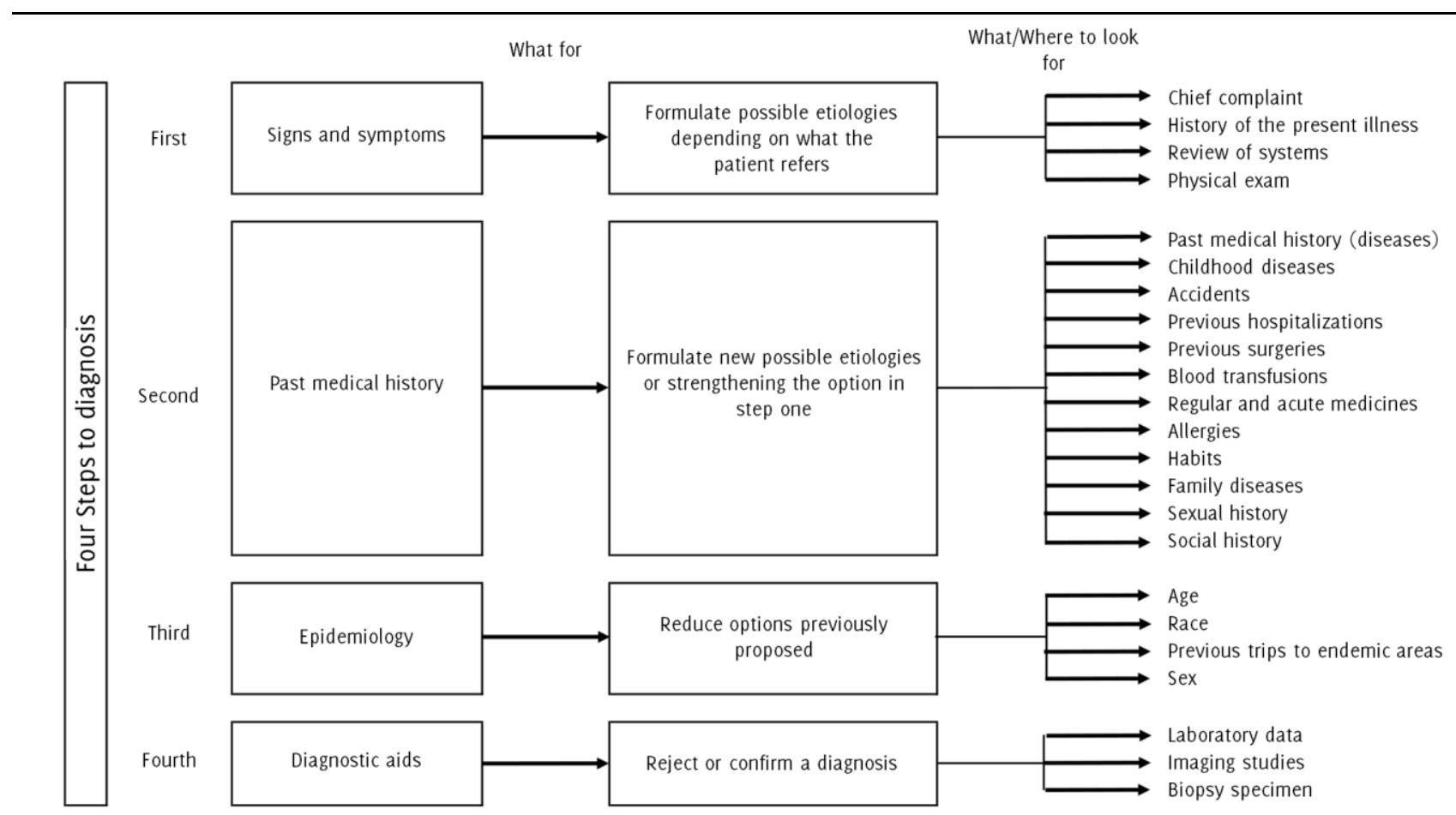




\section{References}

1. Universidad Surcolombiana. Plan de estudio [Internet]. 2005 [cited 7 April 2019. Available from:

https://www.usco.edu.co/archivosUsuarios/12/facultades/plan_estudios_medicinausc0.pdf

2. Hospital Universitario Hernando Moncaleano Perdomo. Manual de induccion y reinducción hospital universitario Hernando Moncaleano Perdomo [Internet]. Neiva; 2014. Available from: http://www.huhmp.gov.co/dotnetnuke/LinkClick.aspx?fileticket=guWNjLNuT51\% 3 Dattabi $d=370$ ctlanguage $=e s-\mathrm{CO}$

3. Argente H. Semiologia medica. 2nd ed. Panamericana; 2004.

4. Kakisaka Y, Kakisaka Y, Fujikawa M, Gaillard S. Writing Case Reports: Teaching and Tuition Techniques, and the Improvement of Clinical Diagnostic Reasoning. Int J Med Students. 2016 Dec; 4(3):88-0.

5. Kasper DL, Fauci AS, Hauser SL, Longo DL, Jameson JL, Loscalzo, J. Harrison: principios de medicina interna. 19th ed. 1950.
6. Suroś Forns J, Suroś Batllo' J, Suroś Batllo A. Semiologiá medica y ténica exploratoria. Barcelona: Salvat; 1984.

7. Ilizástigui Dupuy F, Rodríguez Rivera L. El Método Clínico. Revista Electrónica de las Ciencias Médicas en Cienfuegos [Internet]. 2019 [cited 6 March 2019]. Available from: http://www.medigraphic.com/pdfs/finlay/fi-2017/fi171c.pdf

8. Kovacs G, Croskerry P. Clinical Decision Making: An Emergency Medicine Perspective. Acad Emerg Med. 1999 Sep;6(9):947-52.

9. Cediel Angel R. Semiologia medica. 8th ed. Editorial medica celsus; 2019.

10. Lozano J, Mejia G. Semiología general. 5th ed. medellin: Andina; 2001.

11. Cortina C. Historia clinica, Metodología didactica. Panamericana; 2003.

12. McCee S. Evidence-based physical diagnosis 4th ed. Elsevier; 2017.

13. Henderson M, Tierney L. Historia clínica del paciente: método basado en evidencias. McGraw Hill; 2007.

\section{Acknowledgments}

We want to thank Surcolombiana University and the University Hospital of Neiva for helping us to improve our clinical skills. Also, we thank Anthony Douglas and Heidy Escobar for their kindness and valuable participation in knowledge generation.

Conflict of Interest Statement at Funding

The Authors have no funding, financial relationships or conflicts of interest to disclose.

Author Contributions

Conceptualization: JD and LL. Methodology: JD and LL. Writing original draft: JD and LL

Cite as:

Sendoya Vargas JD, Fernandez Camacho LL. How to Approach a Clinical Case from a Medical Student Perspective. Int J Med Students. 2019;7(1):15-17. 